\title{
EFEITOS NA CULTURA DO TRIGO DA ROTAÇÃO COM MILHO E ADUBOS VERDES, NA PRESENÇA E NA AUSÊNCIA DE ADUBAÇÃO NITROGENADA ${ }^{(1)}$
}

\author{
ORIVALDO ARF ${ }^{(2)}$, LUZIA SALUSTIANO DA SILVA ${ }^{(2)}$, SALATIÉR BUZETTI ${ }^{(3)}$, \\ MARLENE CRISTINA ALVES ${ }^{(3)}$, MARCO EUSTÁQUIO DE SÁ(2), RICARDO ANTONIO \\ FERREIRA RODRIGUES ${ }^{(3)} \&$ FERNANDO BRAZ TANGERINO HERNANDEZ ${ }^{(3)}$
}

\begin{abstract}
RESUMO
O presente trabalho foi realizado no município de Selvíria (MS), sob latossolo vermelho-escuro, epieutrófico álico, textura argilosa, precipitação média anual de $1.370 \mathrm{~mm}$ e temperatura média anual de $23,5^{\circ} \mathrm{C}$. Seu objetivo foi avaliar os efeitos na cultura do trigo e nas propriedades físicas e químicas do solo, da incorporação da fitomassa proveniente de milho, lablabe e mucuna-preta em cultura solteira e intercalada ao milho, na presença e na ausência de adubação nitrogenada $\left(35 \mathrm{~kg} \cdot \mathrm{ha}^{-1}\right)$. Observou-se resposta positiva do trigo aos adubos verdes, principalmente do lablabe e da mucuna-preta em cultura solteira, e não se obteve resposta à adubação nitrogenada em adição à incorporação da fitomassa dessas culturas, assim como não se caracterizou efeito nas propriedades físicas e químicas do solo.
\end{abstract}

Termos de indexação: trigo, adubação verde, nitrogênio, sucessão de culturas.

\section{ABSTRACT \\ WHEAT CROP AS AFFECTED BY THE INCORPORATION OF CORN AND GREEN MANURE TO THE SOIL, WITH AND WITHOUT NITROGEN FERTILIZATION}

This trial was carried out at Selvíria county, State of Mato Grosso do Sul, Brazil, on allic, dark red, clayey latosol. The mean yearly is about $1,370 \mathrm{~mm}$ and temperature is $23.5^{\circ} \mathrm{C}$. The rainfall goal was to evaluate the physical and chemical properties of a soil where corn

\footnotetext{
(1) Recebido para publicacação em 2 de junho de 1998 e aceito em 28 de julho de 1999. Apoio financeiro da FAPESP.

(2) Departamento de Fitotecnia, Economia e Sociologia Rural, Faculdade de Engenharia/UNESP, Avenida Brasil, 56, Caixa Postal 31, 15385-000 Ilha Solteira (SP).

(3) Departamento de Ciência do Solo e Engenharia Rural, Faculdade de Engenharia/UNESP, Ilha Solteira (SP).
} 
and green manure were incorporated, with or without $\mathrm{N}$ fertilization $\left(35 \mathrm{~kg}^{-\mathrm{ha}^{-1}}\right)$ and their effects on wheat crop. The wheat positive response was greater with lab lab and velvet bean in single crop, but there was no response to $\mathrm{N}$ fertilization when the crop residues were incorporated to the soil. Physical and chemical properties of the soil were not affected by the treatments.

Index terms: wheat, green manure, nitrogen, crop rotation.

\section{INTRODUÇÃO}

A melhoria da fertilidade dos solos para fins agrícolas, através do uso da adubação verde, constitui prática utilizada desde antes da era cristã por gregos, romanos e chineses. Os gregos cultivavam favas e os romanos, tremoços, com o objetivo de favorecer as culturas subseqüentes por meio de sua incorporação ao solo (Granato, 1925, citado por Tanaka, 1981). No Brasil, a adubação verde já foi mais adotada. Com a atual recessão econômica do País, associada à crescente preocupação com o efeito do uso indiscriminado de fontes minerais de $\mathrm{N}$ sobre o ambiente, despertou-se o interesse pela utilização de adubos verdes como fonte alternativa de nitrogênio para as culturas.

A incorporação de adubo verde promove, ao longo dos anos, aumento no conteúdo de matéria orgânica do solo, cuja magnitude varia com a quantidade e com a qualidade do adubo verde, condições edafoclimáticas e práticas culturais utilizadas (Ventura \& Watanabe, 1993).

Na cultura do trigo, Barbo \& Fabrício (1981) observaram melhoria na fertilidade do solo com a incorporação de mucuna-preta, guandu, crotalária e lablabe, sem que a adubação verde influenciasse o rendimento de grãos. Já Badaruddin \& Meyer (1990) verificaram que, com o uso de leguminosas forrageiras, aumentou a absorção de nitrogênio e o rendimento de grãos do trigo cultivado em sucessão, em relação aos tratamentos com pousio ou incorporação de palha de trigo. O efeito da rotação com leguminosas foi comparável ao tratamento com a adição de 150 kg.ha- ${ }^{-1}$ de N.
Com o objetivo de avaliar a capacidade de fornecimento de nitrogênio $\left({ }^{15} \mathrm{~N}\right)$ pela espécie Lens culinaris, para o trigo, em relação ao sulfato de amônio, Bremer \& Kessel (1992) verificaram que, embora a assimilação do fertilizante mineral (34\%) tenha sido maior que a do adubo verde (19\%), a contribuição de ambas as fontes foi pequena, não representando $10 \%$ do total do nutriente absorvido pelo trigo. Já Rees et al. (1993), avaliando o efeito da adição de quantidades crescentes de Pisum arvense, observaram que o aproveitamento de $\mathrm{N}$ pela cultura do trigo variou de 15 a $23 \%$ do total de $\mathrm{N}$ adicionado pelo adubo verde, mostrando-se a quantidade de $\mathrm{N}$ fornecida pelo adubo verde diretamente relacionada à quantidade de fitomassa incorporada ao solo.

O uso combinado de adubos minerais e de adubação verde constitui uma prática de manejo por meio da qual se procura preservar a qualidade ambiente sem prescindir da obtenção de produtividade elevada para as culturas. De acordo com Peterson \& Varvel (1989) e Rekhi \& Bajwa (1993), a associação entre fontes orgânicas e minerais é capaz de aumentar o rendimento das culturas, comparativamente ao uso exclusivo de uma única fonte.

Segundo Fageria (1983), a capacidade intrínseca de produção agrícola dos solos está íntima e diretamente relacionada com seus teores de matéria orgânica e de nitrogênio; entretanto, é difícil manter um nível satisfatório de ambos na maioria dos solos cultivados. Assim, os métodos de adição e de manutenção de matéria orgânica devem ser considerados com antecipação em todos os programas de manejo dos solos cultivados. 
Com o objetivo de contribuir com mais informações sobre esse tema, desenvolveu-se o presente trabalho, que teve por objetivo avaliar, no solo e na planta de trigo, os efeitos da incorporação da fitomassa originária da cultura de milho, mucuna-preta e lablabe, na presença e na ausência de adubação nitrogenada em cobertura.

\section{MATERIAL E MÉTODOS}

$\mathrm{O}$ ensaio foi instalado em área experimental pertencente à Faculdade de Engenharia de Ilha Solteira - UNESP, localizada no município de Selvíria (MS), apresentando como coordenadas geográficas $51^{\circ} 22^{\prime}$ de longitude oeste de Greenwich e $20^{\circ} 22^{\prime} \mathrm{de}$ latitude sul, com altitude de 335 metros. O solo do local é do tipo latossolo vermelho-escuro, epieutrófico álico, textura argilosa. A precipitação média anual é de $1.370 \mathrm{~mm}$, a temperatura média anual, de $23,5^{\circ} \mathrm{C}$, e a umidade relativa do ar está entre 60 e 70\% (média anual).

As características químicas do solo, determinadas antes da instalação do ensaio, apresentaram os seguintes resultados: $\mathrm{pH}\left(\mathrm{CaCl}_{2}\right)=4,6 ; 24 \mathrm{~g} \cdot \mathrm{kg}^{-1} \mathrm{de}$ M.O.; 26 mg.dm ${ }^{-3}$ de P (resina); 1,7; 20,0; 3,0 e 38,0 $\mathrm{mmol}_{\mathrm{c}} \cdot \mathrm{dm}^{-3} \mathrm{de} \mathrm{K}, \mathrm{Ca}, \mathrm{Mg}$ e $\mathrm{H}+\mathrm{Al}$ respectivamente, e $40 \%$ de saturação por bases.

Realizou-se o preparo do solo por uma aração e duas gradagens, sendo a primeira logo após a aração e a segunda, pouco antes da semeadura. Durante o preparo do solo, aplicaram-se 3 t.ha ${ }^{-1}$ de calcário dolomítico, metade da dose antes da aração, metade antes da primeira gradagem. A semeadura do milho foi mecânica em 7-12-94, utilizando-se o espaçamento de $0,90 \mathrm{~m}$ nas entrelinhas e cerca de seis a sete sementes/metro de sulco, objetivando obter uma população de cerca de 50.000 plantas/hectare.

Quadro 1. Valores médios da matéria seca do milho, mucuna-preta e lablabe em cultivo solteiro ou em consorciação, na região de Selvíria (MS), 1994/95

\begin{tabular}{|c|c|c|c|c|}
\hline \multirow[t]{2}{*}{ Tratamentos } & \multicolumn{2}{|c|}{ Milho } & \multirow{2}{*}{$\begin{array}{l}\begin{array}{l}\text { Mucuna-preta } \\
\text { ou lablabe }\end{array} \\
\mathrm{kg} . \mathrm{h}\end{array}$} & \multirow{2}{*}{$\begin{array}{c}\begin{array}{c}\text { Matéria seca } \\
\text { total }\end{array} \\
\end{array}$} \\
\hline & g.planta ${ }^{-1}$ & $\mathrm{~kg} \cdot \mathrm{ha}^{-1}$ & & \\
\hline 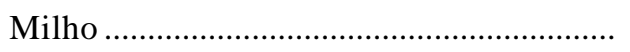 & 83,63 & 4.290 & - & $4.290 \mathrm{~d}$ \\
\hline Milho + mucuna-preta aos 75 DAS $^{(1)} \ldots \ldots .$. & 93,47 & 4.795 & $6.321 \mathrm{a}$ & $11.116 \mathrm{a}$ \\
\hline Milho + mucuna-preta aos 100 DAS ....... & 91,15 & 4.676 & $3.695 b$ & $8.372 b$ \\
\hline Milho + lablabe aos 75 DAS ......................... & 91,76 & 4.707 & $973 c$ & $5.555 \mathrm{~cd}$ \\
\hline Milho + lablabe aos 100 DAS ....................... & 83,17 & 4.266 & $123 c$ & $4.390 \mathrm{~d}$ \\
\hline Lablabe & - & - & $7.340 \mathrm{a}$ & $7.340 \mathrm{c}$ \\
\hline 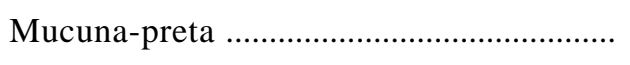 & - & - & $7.974 \mathrm{a}$ & $7.974 b$ \\
\hline F & $0,94 \mathrm{~ns}$ & $0,94 \mathrm{~ns}$ & $73,95 * *$ & $25,27 * *$ \\
\hline $\mathrm{CV}(\%)$ & 11,74 & 11,74 & 17,61 & 14,12 \\
\hline 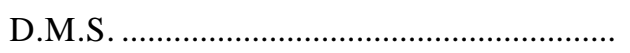 & - & - & 1.784 & 2.259 \\
\hline
\end{tabular}

(1) Dias após a semeadura do milho. ns: não significativo. **: significativo ao nível de $1 \%$. Médias seguidas de mesma letra, na coluna, não diferem estatisticamente entre si pelo teste de Tukey a $5 \%$ de probabilidade. 
Semearam-se mucuna-preta e lablabe, no sistema de cultivo solteiro, sem adubação, no mesmo dia da semeadura do milho, no espaçamento de 0,90 $\mathrm{m}$ e utilizando-se sete e dez sementes viáveis/metro respectivamente. Posteriormente, aos 75 e aos 100 dias após a emergência do milho, semearam-se a mucuna-preta e o lablabe na entrelinha de cultivo, de maneira semelhante ao cultivo solteiro.

Após a colheita do milho, na época de florescimento pleno da mucuna-preta ou lablabe, em cada tratamento, a área foi roçada mecanicamente. Quando a mucuna-preta, semeada aos 100 dias após o milho, atingiu o florescimento pleno, realizou-se sua roçagem mecânica e gradagem na área experimental para pré-incorporação das plantas de milho, lablabe e mucuna-preta. Os valores médios da matéria seca incorporada encontram-se no Quadro 1. Próximo da semeadura do trigo, o solo foi preparado com uma aração, com arado de discos, e duas gradagens, sendo a primeira logo após a aração e a segunda pouco antes da semeadura.

Realizou-se a semeadura do trigo, cultivar IAC 60-Centenário, mecanicamente, em 4-7-95, nas parcelas onde, anteriormente, existia milho, milho + mucuna-preta, milho + lablabe, mucuna-preta e lablabe. $\mathrm{O}$ atraso na semeadura ocorreu em vista de a incorporação dos restos culturais do milho ou da fitomassa dos adubos verdes ter-se feito na época de florescimento da mucuna-preta. A adubação básica foi constituída por $280 \mathrm{~kg} \cdot \mathrm{ha}^{-1}$ da formulação 4-30-10 $+0,4 \%$ de Zn. Utilizou-se o espaçamento de $0,20 \mathrm{~m}$ nas entrelinhas e cerca de 400 sementes viáveis/metro quadrado.

O delineamento experimental foi em blocos casualizados, sendo os tratamentos constituídos pela combinação do efeito da incorporação de restos culturais de milho, mucuna-preta e lablabe, no desenvolvimento do trigo, na presença e na ausência de adubação nitrogenada. Cada parcela (tratamento principal) foi constituída por 44 linhas de trigo com $10 \mathrm{~m}$ de comprimento e subdivididas no sentido longitudinal em duas subparcelas, ou seja, tratamento secundário formado pela aplicação ou não de $35 \mathrm{~kg} \cdot \mathrm{ha}^{-1} \mathrm{de}$
$\mathrm{N}$, na forma de uréia, em cobertura, aos 24 dias após a emergência das plantas.

Efetuou-se o controle de plantas daninhas pela aplicação do herbicida Pendimenthalin (1.000 g.ha-1 do i.a.) em pré-emergência e Bentazon (720 g.ha-1 do $^{-1}$ i.a.) aos 23 dias após a emergência das plantas.

Durante o desenvolvimento da cultura, realizaram-se os demais tratos culturais e fitossanitários, recomendados para a cultura do trigo.

Foram realizadas as seguintes avaliações:

Características químicas do solo - Por ocasião do florescimento, coletaram-se amostras de solo na profundidade de 0-20 cm, na área útil das parcelas, de acordo com Raij \& Quaggio (1983).

Características físicas do solo - Foram avaliadas, também na época de florescimento, com duas repetições por parcela, nas profundidades de 0-10, 10 20, 20-30 e 30-40 cm, a densidade do solo (Blake, 1965), a porosidade total, a macro- e a microporosidade (Vomocil, 1965).

\section{Características da planta:}

a) Massa seca - Por ocasião do florescimento pleno, coletaram-se as plantas ao acaso, 0,30 m de linha, em dois pontos na área das subparcelas, levando-as para o laboratório acondicionadas em sacos de papel e deixando-as para secagem em estufa de ventilação forçada à temperatura de $60-70^{\circ} \mathrm{C}$ durante três dias.

b) Teores de macronutrientes - Utilizaram-se as plantas coletadas para determinação da massa seca. Após a secagem em estufa de ventilação forçada, o material foi submetido à moagem em moinho do tipo Willey e, posteriormente, sofreu digestões sulfúrica e nitroperclórica, conforme método de Sarruge \& Haag (1974).

c) Altura da planta - Determinada na época de maturação como sendo a distância $(\mathrm{cm})$ do nível do solo ao ápice da espiga, excluindo as aristas, e levando-se em consideração a média de diferentes pontos em cada subparcela. 
d) Grau de acamamento - Obteve-se, por meio de observações visuais, na fase de maturação, utilizando-se a seguinte escala de notas: 0: sem acamamento; 1 : até $5 \%$ de plantas acamadas; $2: 5$ a $25 \%$; $3: 25$ a $50 \%$; $4: 50$ a $75 \%$, e $5: 75$ a $100 \%$ de plantas acamadas.

e) Número de grãos por espiga - Na colheita, coletaram-se quinze espigas, na área útil de cada subparcela, acondicionaram-nas em sacos de papel, devidamente identificadas, levando-as ao laboratório para avaliação.

f) Produção de grãos - As plantas da área útil de cada subparcela foram colhidas manualmente; em seguida, fez-se a trilhagem mecânica. Determinou-se a massa de grãos obtidos, e os dados foram transformados em kg.ha-1 (13\% base úmida).

Massa de 1.000 grãos (g) - Foi determinada mediante a coleta, ao acaso, e pesagem de duas amostras de 1.000 grãos de cada subparcela (13\% base úmida).

Peso hectolítrico (PH) - A massa de $100 \mathrm{~L}$ de grãos foi determinada em balança especial com teor de água dos grãos corrigidos para 13\% (base úmida), utilizando-se duas amostras por subparcela.

\section{RESULTADOS E DISCUSSÃO}

Os resultados da análise das características físicas das amostras de solo retiradas na época de florescimento do trigo acham-se no Quadro 2. Verifica-se que não houve influência dos tratamentos, corroborando com Arzeno (1990), Barreto (1991) e Alves et al. (1994). Os autores mencionam que o pouco tempo de cultivo com o sistema de rotação de culturas pode ser a explicação para o ocorrido.

Os resultados da análise química das amostras de solo retiradas na época de florescimento do trigo estão no Quadro 3. Analisando o teor de matéria orgânica, observa-se que, apesar de incorporadas ao solo diferentes quantidades de matéria seca (Quadro 1), não houve alterações no seu teor nos diferentes tratamentos utilizados. Provavelmente, houve mineralização e possíveis perdas e/ou o tempo decorrido entre a incorporação dos adubos verdes e a avaliação efetuada foi insuficiente para que ocorresse adequada decomposição do material orgânico. A variação nos teores de carbono orgânico total, principal constituinte da matéria orgânica do solo, em determinado período, é expressa por

$$
\mathrm{dc} / \mathrm{dt}=-\mathrm{KC}+\mathrm{A},
$$

onde A representa a taxa de adição (t.ha ${ }^{-1} \cdot$ ano $\left.^{-1}\right)$ e $\mathrm{K}$, a taxa de decomposição anual do carbono orgânico total.

Em solo sob condição natural, o conteúdo de carbono orgânico total encontra-se estável, em vista da igualdade das quantidades adicionadas e perdidas anualmente. Em condições de solo cultivado, portanto, essa variação (entre adição e perdas) estará em função do sistema de manejo do solo e das culturas, bem como de condições específicas do solo e clima (Bayer \& Mielniczuk, 1997). Kiehl (1985) afirma que os adubos verdes, após incorporados, tendem a decompor-se e liberar rapidamente os nutrientes. Para os demais parâmetros de fertilidade do solo, de modo geral, não se observaram diferenças entre os tratamentos utilizados, com exceção do potássio, cujas parcelas anteriormente cultivadas com milho apresentaram o maior teor, os tratamentos com adubos verdes (mucuna-preta ou lablabe), valores menores, pois não receberam adubação potássica no momento de sua semeadura, e os tratamentos com milho + adubo verde, teores intermediários. Em geral, pode-se dizer que as características químicas do solo no momento de maior exigência em nutrientes, ou seja, florescimento e frutificação da cultura, eram favoráveis ao cultivo, lembrando que os valores das características químicas - Quadro 3 - referem-se à coleta de solo na entrelinha da cultura e que o fertilizante foi aplicado no sulco de semeadura. 
Quadro 2. Resultados da análise das características físicas das amostras de solo retiradas na época de florescimento do trigo

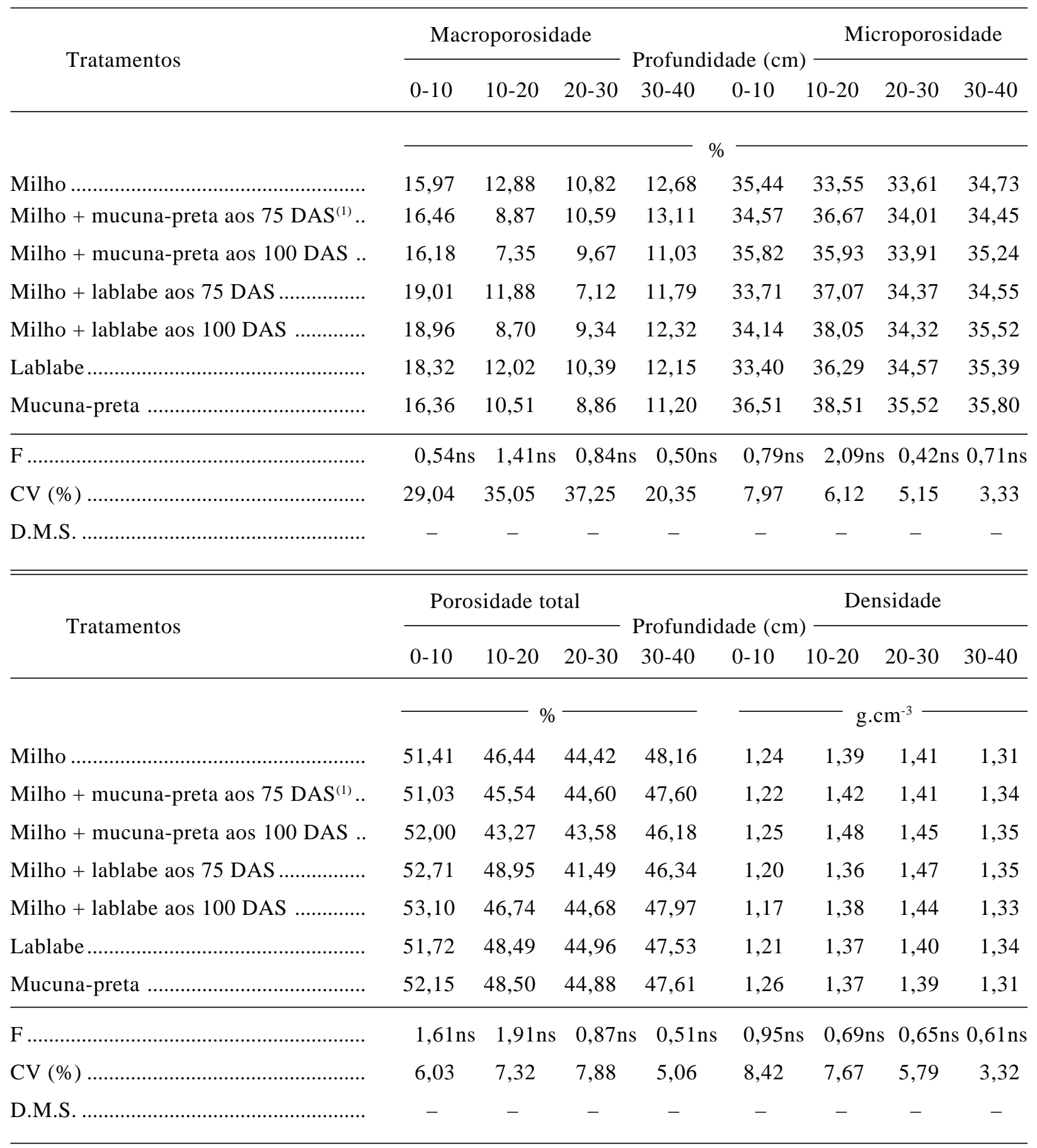

(1) Dias após a semeadura do milho. ns: não significativo. 
Os resultados da avaliação da matéria seca e dos teores de macronutrientes na parte aérea do trigo encontram-se no Quadro 4. Pode-se observar a influência dos restos culturais na matéria seca de plantas na qual os tratamentos com lablabe e mucuna-preta proporcionaram a obtenção de maior quantidade de matéria seca; os tratamentos com milho + mucuna-preta (75 ou 100 DAS) apresentaram valores intermediários, sendo os menores valores obtidos nos tratamentos milho solteiro e milho + lablabe aos 75 ou 100 DAS. Esses tratamentos - Quadro 4 - receberam também quantidade pequena de matéria seca do adubo verde em incorporação, comparativamente aos tratamentos milho + mucuna-preta, mucuna-preta ou lablabe em regime solteiro.

Quanto à avaliação do teor de nitrogênio na parte aérea do trigo, não houve efeito da adubação em cobertura, mas sim da interação adubação em cobertura versus restos culturais (Quadro 4), estando os desdobramentos no Quadro 5.
Mediante a análise de restos culturais dentro de adubação em cobertura, verifica-se efeito significativo entre os tratamentos apenas na presença da adubação nitrogenada, em que o tratamento milho solteiro apresentou o menor teor de $\mathrm{N}$, diferindo apenas do tratamento milho + mucuna-preta aos 75 DAS, demonstrando que a mucuna-preta semeada aos 75 DAS, nas entrelinhas do milho, foi efetiva no fornecimento de N, já que houve, neste caso, boa produção de massa. Fato interessante é que seria esperado um comportamento semelhante em relação aos tratamentos lablabe e mucuna-preta, em regime solteiro, tendo em vista a alta produção de massa; entretanto, neles não houve adubação, tanto na semeadura como em cobertura, o que ocorreu no tratamento milho + mucuna-preta e nos outros. Salienta-se que, naqueles consorciados, a produção de massa dos demais tratamentos foi inferior ao tratamento milho + mucuna aos 75 DAS.

Quadro 3. Resultados da análise química das amostras de solo $(0-20 \mathrm{~cm})$ retiradas na época de florescimento do trigo

\begin{tabular}{|c|c|c|c|c|c|c|c|}
\hline Tratamentos & M.O. & $\mathrm{pH}$ & $P$ resina & $\mathrm{K}$ & $\mathrm{Ca}$ & $\mathrm{Mg}$ & $\mathrm{V}$ \\
\hline & g. $\mathrm{kg}^{-1}$ & $\mathrm{CaCl}_{2}$ & $\mathrm{mg} \cdot \mathrm{dm}^{-3}$ & $\longrightarrow$ & $\mathrm{mmol}_{\mathrm{c}} \cdot \mathrm{dm}^{-3}$ & - & $\%$ \\
\hline Milho & 25,7 & 5,2 & 24 & $1,5 \mathrm{a}$ & 29,0 & 12,3 & 58 \\
\hline Milho + mucuna-preta aos $75 \mathrm{DAS}^{(1)}$ & 25,5 & 5,1 & 17 & $1,2 \mathrm{abc}$ & 25,5 & 13,5 & 55 \\
\hline Milho + mucuna-preta aos 100 DAS & 25,0 & 5,2 & 17 & $1,3 \mathrm{ab}$ & 29,5 & 14,7 & 59 \\
\hline Milho + lablabe aos 75 DAS .............. & 23,2 & 5,1 & 24 & $1,2 \mathrm{abc}$ & 27,5 & 12,0 & 55 \\
\hline Milho + lablabe aos 100 DAS ........... & 24,0 & 5,0 & 16 & $1,4 \mathrm{ab}$ & 23,5 & 13,0 & 55 \\
\hline Lablabe & 24,5 & 5,2 & 19 & $0,9 \mathrm{bc}$ & 27,0 & 16,7 & 59 \\
\hline 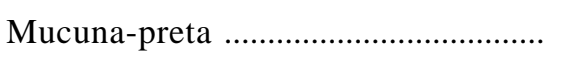 & 23,0 & 5,0 & 19 & $0,8 \mathrm{c}$ & 24,5 & 12,0 & 54 \\
\hline $\mathrm{F}$ & $1,35 \mathrm{~ns}$ & $0,82 \mathrm{~ns}$ & s $\quad 0,76 \mathrm{~ns}$ & $6,19^{* *}$ & $1,27 \mathrm{~ns}$ & $0,88 \mathrm{~ns}$ & $0,76 \mathrm{~ns}$ \\
\hline $\mathrm{CV}(\%)$ & 7,61 & 3,73 & 37,58 & 16,06 & 14,01 & 27,53 & 8,70 \\
\hline D.M.S & - & - & - & 0,05 & - & - & - \\
\hline
\end{tabular}

${ }^{(1)}$ Dias após a semeadura do milho. ns: não significativo; ** significativo ao nível de $1 \%$ pelo teste $\mathrm{F}$. 
Quadro 4. Valores médios da matéria seca de plantas e teores de nutrientes na parte aérea do trigo, em função da incorporação dos restos culturais de milho e/ou mucuna-preta e lablabe, e adubação nitrogenada em cobertura, na região de Selvíria (MS), 1995

\begin{tabular}{|c|c|c|c|c|c|c|c|}
\hline \multirow{2}{*}{ Tratamentos } & \multirow{2}{*}{$\begin{array}{c}\text { Matéria seca } \\
\text { de plantas }\end{array}$} & \multicolumn{6}{|c|}{ Teores de nutrientes } \\
\hline & & $\mathrm{N}$ & $\mathrm{P}$ & $\mathrm{K}$ & $\mathrm{Ca}$ & $\mathrm{Mg}$ & $\mathrm{S}$ \\
\hline Adubação em cobertura & g. $\mathrm{m}^{-1}$ de linha & & & g.k & - & & \\
\hline 0 kg.ha- ${ }^{-1}$ de $\mathrm{N}$ & 87,03 & 21,62 & 3,37 & $31,62 b$ & 3,30 & $2,25 b$ & $1,90 \mathrm{~b}$ \\
\hline 35 kg.ha- ${ }^{-1}$ de $\mathrm{N}$ & 94,53 & 24,66 & 3,51 & $34,74 \mathrm{a}$ & 3,36 & $2,47 \mathrm{a}$ & $2,08 \mathrm{a}$ \\
\hline \multicolumn{8}{|l|}{ Restos culturais } \\
\hline Milho & $74,75 \mathrm{c}$ & 22,62 & $3,72 \mathrm{a}$ & 34,91 & 3,40 & 2,43 & $1,98 \mathrm{ab}$ \\
\hline Milho + mucuna-preta aos 75 DAS $^{(1)} \ldots \ldots \ldots$ & $90,17 \mathrm{bc}$ & 24,41 & $3,76 \mathrm{a}$ & 33,72 & 3,25 & 2,19 & $1,96 \mathrm{ab}$ \\
\hline Milho + mucuna-preta aos 100 DAS ......... & $88,12 \mathrm{bc}$ & 21,96 & $3,43 \mathrm{ab}$ & 33,72 & 3,20 & 2,25 & $1,91 \mathrm{ab}$ \\
\hline 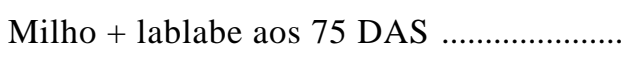 & $71,56 \mathrm{c}$ & 21,96 & $3,44 \mathrm{ab}$ & 32,06 & 3,45 & 2,16 & $1,91 \mathrm{ab}$ \\
\hline Milho + lablabe aos 100 DAS ........................ & $79,25 \mathrm{c}$ & 23,88 & $3,42 \mathrm{abc}$ & 32,06 & 3,15 & 2,22 & $1,80 \mathrm{~b}$ \\
\hline 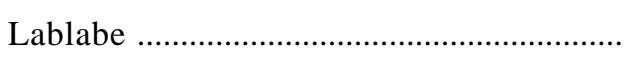 & $120,02 \mathrm{a}$ & 23,23 & $3,27 \mathrm{bc}$ & 33,96 & 3,30 & 2,58 & $2,24 \mathrm{a}$ \\
\hline 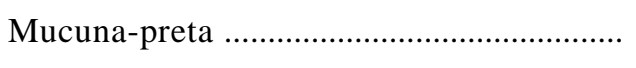 & $111,60 \mathrm{ab}$ & 23,93 & $3,03 \mathrm{c}$ & 31,82 & 3,55 & 2,67 & $2,14 \mathrm{ab}$ \\
\hline \multicolumn{8}{|l|}{$\mathbf{F}$} \\
\hline Adubação em cobertura ................................ & $2,68 \mathrm{~ns}$ & $38,44 * *$ & $4,09 *$ & $15,84 * *$ & $0,19 \mathrm{~ns}$ & $4,17 *$ & $9,26^{*}$ \\
\hline 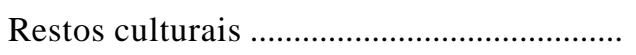 & $9,33 * *$ & $2,32 * *$ & $7,79 * *$ & $1,32 \mathrm{~ns}$ & $0,70 \mathrm{~ns}$ & $1,99 \mathrm{~ns}$ & $3,81 *$ \\
\hline Adubação x restos & $0,19 \mathrm{~ns}$ & $2,64^{*}$ & $0,60 \mathrm{~ns}$ & $0,61 \mathrm{~ns}$ & $0,81 \mathrm{~ns}$ & $1,35 \mathrm{~ns}$ & $1,08 \mathrm{~ns}$ \\
\hline $\mathrm{CV}(\%)$ & 18,88 & 7,92 & 7,38 & 8,84 & 14,61 & 17,33 & 10,87 \\
\hline D.M.S. Adubação em cobertura ................. & - & - & - & 1,59 & - & 0,22 & 0,11 \\
\hline Tuckey $5 \%$ Restos culturais ........................ & 26,55 & - & 0,39 & - & - & - & 0,33 \\
\hline
\end{tabular}

${ }^{(1)}$ Dias após a semeadura do milho. * significativo ao nível de 5\% pelo teste F. ** significativo ao nível de $1 \%$ pelo teste F. ns: não significativo. 
Quadro 5. Desdobramentos das interações significativas da análise da variância referente ao teor de nitrogênio na parte aérea do trigo

Restos culturais

Adubação em cobertura

$0 \mathrm{~kg} \cdot \mathrm{ha}^{-1} \quad 35 \mathrm{~kg} \cdot \mathrm{ha}^{-1}$

Milho

$22,75 \mathrm{aA}$

$22,49 \mathrm{bA}$

Milho + mucuna-preta aos $75 \mathrm{DAS}^{(1)} \ldots \ldots$

$21,70 \mathrm{aB}$

$27,12 \mathrm{aA}$

Milho + mucuna-preta aos 100 DAS ......

$20,74 \mathrm{aA}$

23,19abA

Milho + lablabe aos 75 DAS

$19,25 \mathrm{aB}$

$24,68 \mathrm{abA}$

Milho + lablabe aos 100 DAS

$21,87 \mathrm{aB}$

25,90abA

Lablabe

$21,79 \mathrm{aB}$

$24,68 \mathrm{abA}$

Mucuna-preta

$23,28 \mathrm{aA}$

24,59abA

D.M.S. Restos culturais dentro de adubação em cobertura $=4,03$

Adubação em cobertura dentro de restos culturais $=2,62$

(1) Dias após a semeadura do milho. Médias seguidas de mesma letra, maiúscula na linha e minúscula na coluna, não diferem entre si pelo teste de Tukey ao nível de $5 \%$.

No que se refere ao fósforo, os menores teores foram observados nos tratamentos lablabe e mucuna-preta. Talvez isso possa ser explicado por não ter sido utilizada adubação fosfatada e potássica na semeadura dos adubos verdes em cultivo solteiro, enquanto nos demais tratamentos o milho foi adubado na semeadura.

No que se refere ao $\mathrm{K}, \mathrm{Ca}$ e $\mathrm{Mg}$, observa-se efeito significativo apenas da adubação em cobertura para $\mathrm{K}$ e $\mathrm{Mg}$, cujo uso de $35 \mathrm{~kg} / \mathrm{ha}$ de $\mathrm{N}$ em cobertura propiciou a obtenção de maiores teores dos nutrientes na parte aérea das plantas, possivelmente em vista de melhor desenvolvimento do sistema radicular, o que propiciou a exploração de um volume maior de solo pelas raízes, contribuindo, assim, para o aumento na concentração de $\mathrm{K}$, já que o nível do elemento no solo era baixo (Quadro 3). Isso, entretanto, não se aplica ao $\mathrm{Mg}$.

No caso do enxofre, houve efeito significativo da adubação em cobertura, que propiciou, também, a exemplo do $\mathrm{K}$ e $\mathrm{Mg}$, aumento no teor do nutriente na parte aérea. Já no que se refere aos restos culturais, o menor teor de enxofre foi observado no tratamento milho + lablabe aos 100 DAS, diferindo, porém, significativamente, apenas do tratamento com incorporação de lablabe.

Os valores obtidos na avaliação das características agronômicas do trigo estão no Quadro 6. Verifica-se o efeito dos restos culturais na altura de plantas, possibilitando aos tratamentos lablabe e mucuna-preta obter plantas de trigo de maior altura. Os tratamentos milho + mucuna-preta (75 e 100 DAS) e milho + lablabe aos 100 DAS revelaram valores intermediários, e milho solteiro e milho + lablabe aos 75 DAS apresentaram os menores valores. Pelo Quadro 1, verifica-se que tais tratamentos receberam quantidades pequenas de matéria seca do adubo verde em incorporação. O comportamento entre os tratamentos foi semelhante aos resultados obtidos na avaliação da matéria seca de plantas (Quadro 4). Não se observou efeito dos diferentes tratamentos no acamamento de plantas. 
Quadro 6. Valores médios das características agronômicas do trigo, em função da incorporação dos restos culturais de milho e/ou mucuna-preta e lablabe, e adubação nitrogenada em cobertura, na região de Selvíria (MS), 1995

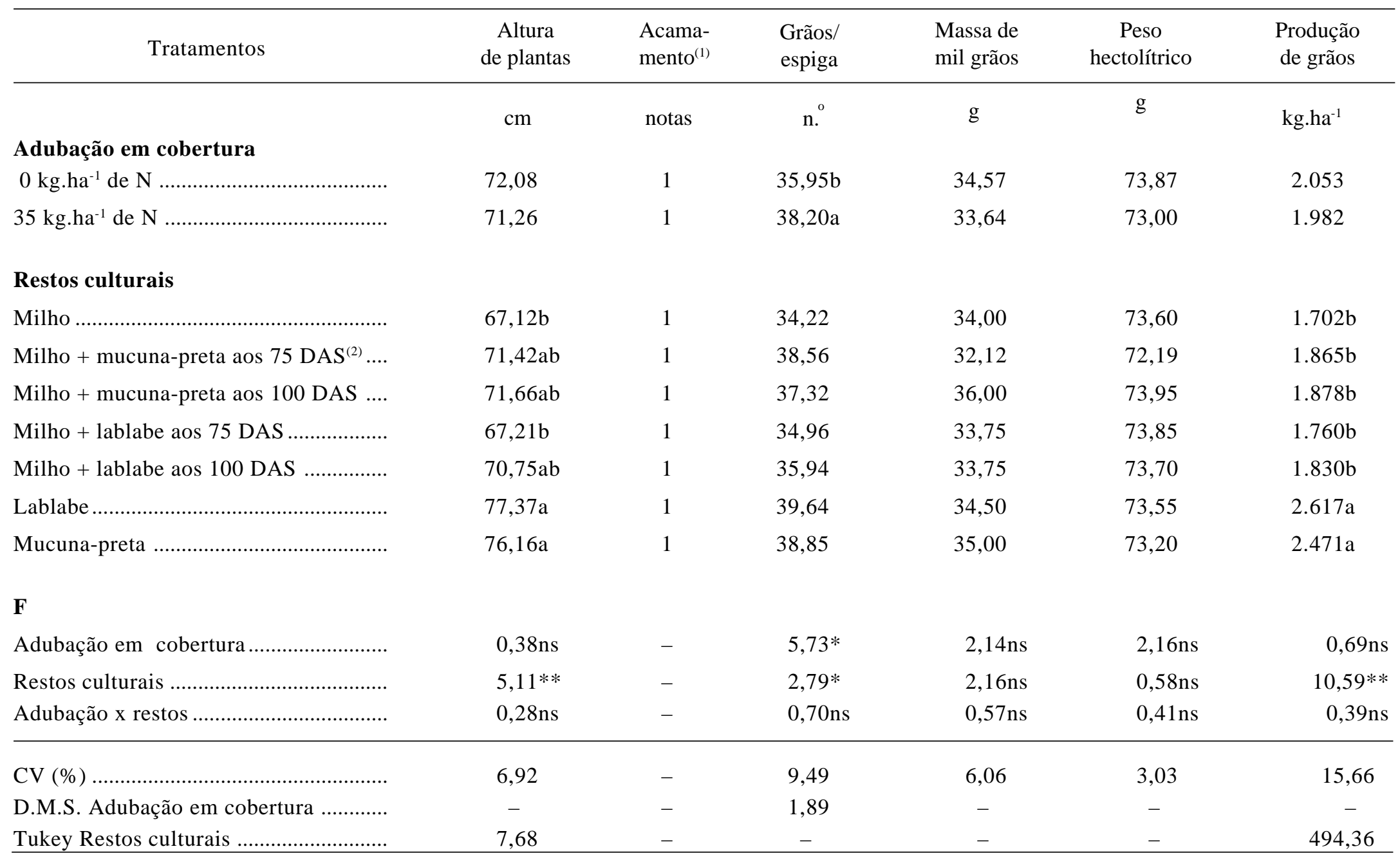

(1) Escala de notas: 1: até 5\% de plantas acamadas; 2: 5 a 25\%; $3: 25$ a 50\%; 4: 50 a 75\% e 5: 75 a 100\% de plantas acamadas. (2) Dias após a semeadura do milho. * significativo ao nível de 5\% pelo teste $\mathrm{F} . * *$ : significativo ao nível de $1 \%$ pelo teste $\mathrm{F}$. ns: não significativo. 
No que se refere ao número de grãos/espiga, massa de 1.000 grãos e peso hectolítrico, observa-se apenas efeito significativo da adubação em cobertura sobre o número de grãos/espiga, em que a aplicação de $35 \mathrm{~kg} \cdot \mathrm{ha}^{-1}$ de $\mathrm{N}$ propiciou valores mais elevados. Quanto ao peso hectolítrico, o valor médio obtido nos diferentes tratamentos foi de $73,43 \mathrm{~g}$, ou seja, abaixo do valor padrão para a cultura (78), em virtude da semeadura tardia da cultura em relação à época recomendada para a região, onde, na fase de enchimento dos grãos, houve ocorrência de condições térmicas menos favoráveis.

No que se refere à produção de grãos, verifica-se - Quadro 6 - que, apesar de a adubação nitrogenada ter propiciado aumento do número de grãos/espiga, não houve diferença na produção de grãos, sendo de 2.053 e $1.982 \mathrm{~kg}$ ha $^{-1}$, respectivamente, na ausência e na presença de adubação nitrogenada. Isso é explicado pelo fato de a massa de mil grãos e o peso hectolítrico não terem acompanhado o número de grãos/espiga, diluindo então tal efeito. Quanto aos restos culturais, a maior produtividade foi obtida nos tratamentos com incorporação de lablabe e mucuna-preta, diferindo significativamente dos demais. A incorporação de lablabe e mucuna-preta possibilitou aumentos de 53,8 e 45,2\% respectivamente, na produtividade do trigo em relação à incorporação de restos culturais de milho. Os resultados concordam com Miranda (1994), que propõe a busca de soluções para viabilizar o cultivo do trigo aumentando sua produtividade e qualidade, indicando a adubação verde como alternativa viável para a cultura. No presente trabalho, não se observou aumento no rendimento do trigo pela associação de fontes orgânicas e inorgânicas de nutrientes, como sugerido por Peterson \& Varvel (1989) e Rekhi \& Bajwa (1993).

\section{CONCLUSÕES}

1. Não foi possível caracterizar os efeitos dos tratamentos nas propriedades físicas e químicas do solo.
2. Os adubos verdes lablabe e mucuna-preta, incorporados ao solo, proporcionaram a maior resposta do trigo, com aumentos de $53,8 \%$ e $45,2 \%$, respectivamente, em relação à incorporação única de restos de culturas de milho.

3. Não houve resposta de trigo à adubação nitrogenada em adição aos restos de cultura incorporados.

\section{REFERÊNCIAS BIBLIOGRÁFICAS}

ALVES, M.C.; VIEIRA, S. R.; CASTRO, O. M. \& LOMBARDI, F. Effects of crop rotation systems with no-tillage in the physical properties of a "Latossolo Roxo". In: WORLD CONGRESS OF SOIL SCIENCE, 15., 1994, Acapulco, México. Anais. Acapulco, Internacional Society of Soil Science, 1994. p.147-148.

ARZENO, J.L. Avaliação física de diferentes manejos em um Latossolo Roxo distrófico. Piracicaba, 1990. 259p. Tese (Doutorado) - Escola Superior de Agricultura "Luiz de Queiroz" - USP, 1990.

BADARUDDIN, M. \& MEYER, D.W. Green-manure legume effects on soil nitrogen, grain yield and nitrogen nutrition of wheat. Crop Science, Madison, 30(4):819825, 1990.

BARBO, C.V.S. \& FABRÍCIO, A.C. Efeito da adubação verde sobre as características do solo e rendimento de grãos da cultura do trigo. In: REUNIÃO DA COMISSÃO NORTE BRASILEIRA DE PESQUISA DE TRIGO, 7., 1981, Ponta Grossa. Reunião. Dourados, EMBRAPAUEPAE, 1981. p.111-117.

BARRETO, A.C. Efeito de sistema de rotação, sucessão e níveis de calagem, sobre características físicas e químicas do solo e no desenvolvimento do sistema radicular e produção de grãos de milho (Zea mays L.). Piracicaba, 1991. $154 \mathrm{p}$. Tese (Doutorado - Escola Superior de Agricultura "Luiz de Queiroz" - USP, 1991.

BAYER, C. \& MIELNICZUK, J. Características químicas do solo afetadas por métodos de preparo e sistemas de cultura. Revista Brasileira de Ciência do Solo, Campinas, 21:105-112, 1997. 
BLAKE, G.L. Bulk density. In: BLACK, C.A.; EVANS, D.D.; WHITE, J.L.; ENSMINGER, L.E. \& CLARCK, F.E., eds. Methods of soil analysis: physical and mineralogical properties, including statistical of measurement and sampling. 1.ed. Madison, American Society of Agronomy, 1965, p.374-390.

BREMER, E. \& KESSEL, C. van. Plant-available nitrogen from lentil and wheat residues during a subsequent growing season. Soil Science Society of America Journal, Madison, 56(4):1155-1160, 1992.

FAGERIA, N.K. Manejo químico do solo. In: Cultura do arroz de sequeiro: fatores afetando a produtividade. Piracicaba, Instituto da Potassa e do Fosfato - Instituto Internacional da Potassa, 1983. p.239-260.

KIEHL, E.J. Fertilizantes orgânicos. Piracicaba, Agronômica Ceres, 1985. 492p.

MIRANDA, G.M. Trigo nacional: do protecionismo ao Mercosul. Londrina, IAPAR, 1994. 24p. (IAPAR. Documento, 17)

PETERSON, T.A. \& VARVEL, G.E. Crop yield as affected by rotation and nitrogen rate. III. Corn. Agronomy Journal, Madison, 81(5):735-738, 1989.

RAIJ, B. van \& QUAGGIO, J.A. Métodos de análise de solo para fins de fertilidade. Campinas, Instituto Agronômico, 1983. 31p. (Boletim Técnico, 81)
REES, R.M.; YAN, L. \& FERGUSON, M. The release and plant uptake of nitrogen from some plant and animal manures. Biology and Fertility of Soils, New York, 15(4):285-293, 1993.

REKHI, R.S. \& BAJWA, M.S. Effect of green manure on the yield, N-uptake and floodwater properties of a flooded rice, wheat rotation receiving ${ }^{15} \mathrm{~N}$ urea on a highly permeable soil. Fertilizer Research, Dordrecht, 34(1):1522, 1993.

SARRUGE, J.R. \& HAAG, H.P. Análises químicas em plantas. Piracicaba, ESALQ, 1974. 56p. (Mimeografado)

TANAKA, R.T. A adubação verde. Informe Agropecuário, Belo Horizonte, 7(81):62-67, 1981.

VENTURA, W. \& WATANABE, I. Green manure production of Azolla microphylla and Sesbania rostrata and their long-term effects on rice yields and soil fertility. Biology and Fertility of Soils, New York, 15(4):241-248, 1993.

VOMOCIL, J.A. Porosity. In: BLACK, C.A.; EVANS, D.D.; WHITE, J.L.; ENSMINGER, L.E. \& CLARCK, F.E., eds. Methods of soil analysis: physical and mineralogical properties including statistics of measurements and sampling. 1.ed. Madison, American Society of Agronomy, 1965. p.299-314. 